\title{
Pembiasaan Literasi di Pesantren Modern Internasional Dea Malela
}

\author{
Juanda \\ Pendidikan Bahasa dan Sastra Indonesia Universitas Samawa \\ juanda_unsa14@yahoo.co.id
}

\begin{abstract}
Abstrak
Dalam The Indonesia Competiveness Report 2011, Indonesia berada di posisi 41, terutama dalam pendidikan dasar dan pendidikan tinggi. Sementara hasil PISA juga menempatkan Indonesia pada posisi 64 dari 72 negara. Dengan laporan dan penelitian tersebut, apakah Indonesia dapat dikatakan siap bersaing dengan Masyarakat Ekonomi ASEAN atau masyarakat global? Kesiapan atau ketidaksiapan sangat dipengaruhi oleh tingkat literasi.

Keterhubungan antara globalisasi dan literasi sangat intim (Kumaravadivelu, 2012). Literasi akan memengaruhi kesuksesan seseorang. Seorang literat pasti memiliki kemampuan dan keterampilan untuk menyongsong masa depan, optimis, dan futurolog. Sebaliknya orang iliterat memandang masa depan dengan pesimistik karena ia tidak memiliki "keistimewaan" atau "kelebihan" menghadapi tantangan zaman. Literasi tidak hanya diartikan literate (melek baca) secara sempit, tetapi juga literasi dimaknai sebagai kemampuan memahami teknologi, media masa, digital, teks, dan sebagainya.

Literasi dapat diperoleh secara informal dan formal. Lazimnya, pelajar atau santri memperoleh literasi di sekolah atau pesantren. Sebagai upaya mempersiapkan santrinya memasuki MEA dan masyarakat global, PMI-DM menyusun suatu program yang disebut "Gemar Membaca." Program ini bertujuan untuk menciptakan pembiasaan dan membangun budaya literasi yang unggul, dinamis, komptetitif, dan komparatif. Adapun sintaks kegiatan yang dilaksanakan, yaitu: pramembaca, membaca, dan pascamembaca. Namun tidak jarang kendala dan tantangan yang dihadapi oleh PMI-DM, seperti pelibatan santri dan ustad/ustazah yang belum optimal, sumber belajar (cetak) dan belum memanfaatkan sumber-sumber seperti jurnal, majalah, bulletin, hasil penelitian, komik, lalu perpustakaan yang masih tahap pembangunan, keragaman latar belakang santri, dan seterusnya.
\end{abstract}

Kata Kunci: pembiasaan, literasi, PMI-DM

\section{PENDAHULUAN}

Pengajaran bahasa memang selalu dipengaruhi oleh arus globalisasi (Kumaravadivelu, 2012: 2-11). Setidaknya terdapat lima perspektif yang dapat digunakan mengapa globalisasi dan bahasa berhubungan, yaitu: (1) the postnational perspective, (2) the postmodern perspective, (3) the postcolonial perspective, (4) the post-transmission perspective, dan (5) the postmethod perspective.

Programme for International Student Assessment (PISA) (OECD, 2012 \& 2015) bisa dijadikan rujukan di mana Indonesia masih sangat tertinggal, tepatnya peringkat 64 dari 72 negara. Peringkat tersebut tampak sangat jauh jaraknya dengan Singapura, Thailand, Macau, Vietnam, atau Malaysia. Hasil ini berbanding lurus dengan The Indonesia Competitiveness Report (WEF, 2011), yang menempatkan Indonesia pada posisis 41 dari 140 negara. Hal ini menunjukkan daya saing yang rendah tersebut, salah 
satu sebabnya sangat dipengaruhi oleh literasi (pembelajaran) (Luke \& Carrington, 2002: 243-244).

Dengan berbagai penelitian tersebut seharusnya menjadi cermin bagi pemerintah agar menyusun kebijakan yang berorientasi perbaikan. Kebijakan harus benar-benar dipastikan implementasinya. Dalam konteks literasi, Menteri Pendidikan dan Kebudayaan telah menerbitkan Permendikbud Nomor 23 Tahun 2015 tentang Penumbuhan Budi Pekerti. Regulasi ini masih bersifat overt, yang diharapkan bersifat covert, yaitu menyentuh dan menyelesaian persoalan pembiasaan atau pembudayaan literasi.

Literasi harus terencana (planned), bukan sebaliknya tidak terencana (unplanned) agar memberi dampak positif terhadap capaian literasi pada masa mendatang atau setidaknya memperbaiki peringkat di PISA ataupun TIMMS. Pada tataran supramakro, kebijakan tidaklah berarti apa-apa, apabila tidak termasyarakatkan dengan baik. Pemasyarakatannya adalah seluruh stakeholder, khususnya sekolah melibatkan diri dan aware.

Literasi yang baik merupakan tiket memasuki kehidupan masyarakat yang nyata (sosial), ekonomi, pendidikan, politik, dan sebagainya (Bialystok, 2003: 152). Bahkan kesuksesan akademik siswa sangat bergantung pada keterampilan litersi yang dikuasinya. Keterampilan tersebut kelak akan menentukan masa depan mereka.

Sadar betapa penting literasi, Pesantren Modern Internasional Dea Malela (PMIDM) kemudian mendesain suatu program yang bertujuan untuk membiasakan dan membudayakan serta meningkatkan literasi santri. Program yang dinamai "Gemar Membaca" ini terbilang baru karena belum genap berusia 1 tahun. Namun sangat patut mendapat apresiasi di tengah Indeks Pembangunan Manusia (2015) Provinsi Nusa Tenggara Barat yang berada di posisi 18 dari 34 provinsi.

Tulisan ini bermaksud mengkaji dan berbagi pengalaman bagaimana program "Gemar Membaca" yang dikelola oleh PMI-DM. Terdapat tiga hal yang dibahas, yaitu: (1) kegiatan pramembaca; (2) kegiatan membaca; (3) kegiatan pascamembaca. Selain itu, kendala dan tantangan yang dihadapi pun diulas dengan maksud menjadi dasar perbaikan.

\section{KAJIAN TEORI}

OECD (2000: x) mendefiniskan literasi sebagai "keterampilan menggunakan informasi baik cetak (printed) maupun tertulis (written) untuk difungsikan dalam masyarakat supaya seseorang mencapai tujuan dan mengembangakn potensi serta pengetahuannya. Lebih lanjut OECD pun mengidentifikasi tiga ranah keterampilan literasi, yakni: (1) literasi prosa (pengetahuan dan keterampilan memahami dan menggunakan informasi dari teks, seperti editorial, cerita, brosur, dan buku-buku petunjuk); (2) literasi dokumen (pengetahuan dan keterampilan menempatkan dan menggunakan informasi, seperti surat lamaran kerja, jadwal transportasi, peta, tabel, diagram, gambar, matrik, dan bagan; dan (3) literasi kuantitatif (pengetahuan dan keterampilan mengoperasikan aritmetik).

Senada dengan definisi tadi, dalam tradisi Manga Jepang, literasi diartikan sebagai kemampuan membaca dan menulis. Salah satu keterampilan tersebut harus dipelajari secara mekanik. Hal ini bermakna bahwa mereka mampu mengaplikasikan keterampilan tadi melalui tulisan (Ingulsrud \& Allen, 2009: 69).

Sementara National Literacy Strategy (NLS) menjelaskan literasi dengan cara melakukan analisis tentang apa yang dapat dilakukan oleh seorang anak. NLS ((Wray, et.al., 2004: 2; Beard, 2002: 38) menetapkan ciri seorang anak literat, yaitu: (1) mampu 
membaca dan menulis dengan lancar dan percaya diri serta memahaminya; (2) mampu membaca dan menilai bacaannya; (3) mampu mengetahui dan memahami unsur fiksi dan puisi; (4) mampu menggunakan teks non-fiksi; (5) mampu memonitor dan membetulkan bacaannya; (6) mampu merencanakan, menyusun draf, merevisi, dan menyunting tulisannya; (7) mampu merangkai kata-kata dan memaknainya serta memperkaya kosakata; (8) mampu memahami bunyi, ejaan, dan kaidah-kaidah bahasa secara tepat; (9) memiliki rasa ketertarikan yang kuat terhadap tulisan. Dari kriteria tersebut, literasi dapat disimpulkan sebagai kemampuan mengakses, memahami, dan menggunakan informasi secara mandiri, tepat, dan bertanggung jawab.

Kemudian Ivanic \& Hamilton (1990) menjelaskan 4 hal tentang literasi. Pertama, baca dan tulis merupakan semua aktivitas sehari-hari. Kedua, literasi merupakan salah satu sarana untuk berkomunikasi, berekspresi, dan menemukan informasi. Ketiga, pengembangan literasi tidak selalu berkaitan dengan usia. Keempat, pembelajaran dan pelibatan komunitas juga ikut berperan meningkatkan literasi. Berkaitan dengan literasi, Teale and Sulzby (Rhyner, Haebig \& West, 2009: 7-8) menyimpulkan: (1) pengembangan literasi diperkenalkan sebelum pembelajaran literasi formal; (2) ada hubungan antara keterampilan reseptif (menyimak dan membaca) dan keterampilan produktif (berbicara dan menulis); (3) fungsi literasi adalah sangat penting bagi perkembangan literasi awal anak-anak; (4) keaktifan anak-anak mengeksplorasi lingkungan dan menciptakan interaksi dengan orang dewasa akan sangat membatu untuk menentukan model pembelajaran literasi; (5) ada hubungan perkembangan usia anak dan pemerolehan literasi.

\section{PEMBAHASAN}

PMI-DM diresmikan pada tanggal 9 Februari 2016, berada di Dusun Pamangong Kabupaten Sumbawa Provinsi Nusa Tenggara Barat. Jaraknya sekitar $40 \mathrm{Km}$ ke arah selatan dari Sumbawa Besar. Di dusun kecil ini banyak melahirkan tokoh, seperti Abdul Qadir Jaelani, Lalu Agga, Ismail, Din Syamsuddin, dan lain-lain. Ismail bergelar Dea Malela, adalah putra seorang ulama yang bernama Abdul Qadir Jaelani. Jika silsilah, ternyata Pengasuh PMI-DM, yaitu Prof. Dr. Din Syamsuddin, M.A., merupakan keturunan ketujuh (www.deamalelafoundation.com).

Di tengah pesantren terdapat makam paman Dea Malela yang bernama Lalu Agga yang bergelar Dea Tuan. Beliau juga seorang dai/ulama terkemuka yang berjasa dalam menyiarkan agama Islam di Tana Samawa. Makamnya tepat berada di tengah PMI-DM.

PMI-DM berdiri pada tahun 2015, dengan visi, yaitu: "Menjadi lembaga pendidikan berkeunggulan (centre for academic excellence) tingkat global untuk melahirkan sumber daya insani beriman yang mandiri, kreatif, inovatif, dan kompetitif." Pada awal, PMI-DM hanya membuka Sekolah Menengah Pertama dengan jumlah 44 santri, yang berasal dari Indonesia, Timor Leste, dan Vietnam. Kemudian tahun akademik 2017/2018, Sekolah Menegah Atas kembali dibuka.

Sebagai pesantren baru, PMI-DM cukup gemilang dengan keberhasilannya menghadirkan para tokoh nasional, seperti Wakil Presiden, Dr. (Hc.). H.M. Yusuf Kalla; MenPAN \& RB, Prof. Dr. Yuddy Crisnandi; Kemendikbud, Anies Baswedan, Ph.D., sebelum digantikan Prof. Dr. Muhadjir Effendy; Kapolri, Tito Karnavian, Ph.D., dan sejumlah tokoh nasional lainnya. Tentu kehadiran tokoh-tokoh nasional tersebut merupakan langkah awal menapaki tingkat global sebagaimana tertuang dalam Buku Panduan Akademik. 
Selain menghadirikan para tokoh nasional tadi, PMI-DM juga mencoba menumbuhkan pembiasaan literasi yang dilakukan oleh segenap Dea Guru, pendidik, santri, tenaga pendidik, juru masak, dan satpam. Bentuk pembiasaan itu salah satunya adalah menyusun program yang dinamai "Gemar Membaca." Secara umum, kegiatan "Gemar Membaca" mempunyai 3 sintaks, yaitu: kegiatan pra-membaca, membaca, dan pascamembaca.

\subsection{Kegiatan Pramembaca, Membaca, dan Pascamembaca}

Dalam prakteknya, kegiatan pramembaca selalu diisi dengan memberikan penjelaskan tujuan membaca yang dikaitkan dengan materi pembelajaran. Setelah itu, ustad/ustazah mengarahkan santri untuk memilih buku bacaaan. Santri tetap diberi kebebasan untuk memilih buku selama masih berkaitan dengan materi pembelajaran. Pada umumnya yang dibaca adalah buku-buku yang berkaitan dengan pembelajaran dalam kelas. Adapun waktu pelaksanaannya dimulai dari Selasa sampai Jumat, selama 15 menit sebelum mengikuti pembelajaran.

Saat kegiatan membaca, santri diminta agar membaca selama waktu yang telah ditetapkan oleh PMI-DM. pada tahap ini, ustad/ustad tidak jarang mengombinasikan model pembelajaran agar santri tidak bosan dan jenuh, misalnya secara mandiri ataupun kelompok.

Hal ini sesuai dengan hasil wawancara di mana ustad/ustazah menyadari kekurangan tersebut, sehingga pascaorientasi diharapkan ada upaya perbaikan yang dilakukan oleh Dea Guru. Alhamdulilah, semua saran dan masukan tadi telah ditindaklanjuti oleh seluruh stakeholder. Memang idealnya, literat tidak hanya dilaksanakan oleh santri, akan tetapi Dea Guru dan pihak terkait juga ikut membaca agar menjadi literat.

Setelah membaca atau kegiatan pascamembaca, santri diminta untuk: (1) mencatat judul, pengarang dan jumlah halaman yang telah dibaca. Semua kegiatan dimasukkan ke dalam jurnal membaca harian. Setelah itu, santri diminta agar melanjutkan membaca buku yang sama. Kemudian buku-buku yang dipinjam atau dibawa ke dalam kelas agar dikembalikan ke perpustakaan. Selanjutnya, ustad/ustadzah melanjutkan materi pembelajaran yang dikaitkan dengan bacaan santri.

Tabel 1: Jurnal Membaca Santri

Nama

\begin{tabular}{|l|l|l|l|l|}
\hline Judul & Pengarang & Genre & Tanggapan & Ttd. Guru \\
\hline & & & & \\
\hline & & & & \\
\hline & & & & \\
\hline & & & & \\
\hline
\end{tabular}

\subsection{Kendala dan Tantangan}

Pada tahap pramembaca hanya dilakukan oleh santri, sehingga tentu menjadi kurang optimal. Ditambah lagi latar belakang santri yang beraneka ragam, ada yang dari Indonesia, Timor Leste, dan Vietnam. Perbedaan ini jelas sedikit tidaknya akan memengaruhi kelancaran komunikasi. Alat komunikasi yang diwajibkan dalam lingkungan PMI-DM adalah bahasa Arab, bahasa Inggris, dan bahasa Indonesia, bahkan ke depan ditambah lagi bahasa Mandarin. Rowe \& Levine (2009: 2) mengemukakan bahwa komunikasi merupakan tindakan yang memengaruhi tindakan orang lain melalui transmisi informasi. 
Dengan keragaman budaya dan sosial, maka tidak jarang santri asing menjadi tersendat komunikasi dan memahami maksud serta arahan ustad/ustazah, bahkan santri yang dari Indonesia sendiri ada yang belum lancar berbahasa Indonesia. Hal ini jelas menjadi tantangan tersendiri untuk menemukan solusi terbaik dalam pengelolaan program "Gemar Membaca."

Ada sejumlah asumsi yang melandasi analisis kontrastif, antara lain: unsur-unsur yang sama antara B1 dan B2 tidak akan menimbulkan interferensi; unsur-unsur yang berbeda antara B1 dan B2 akan menyebabkan kesukaran bagi pembelajar dan dapat menimbulkan interferensi; kesalahan pembelajar dalam proses belajar disebabkan oleh sebagian besar adanya interferensi yang datang dari B1; unsur-unsur yang serupa dan yang berbeda antara B1 dan B2 dapat ditemukan dari usaha membandingkan antara sistem B1 dengan B2; hasil perbandingan itu dapat dijadikan dasar untuk memprediksi kesulitan-kesulitan belajar yang gejalanya dapat dilihat dari kesalahan-kesalahan yang dibuat oleh pembelajar; dan perbandingan antara sistem B1 dan B2 setidak-tidaknya dapat menentukan urutan kesulitan, yakni makin besar perbedaan B1 dan B2 makin besar pula kesulitan yang mungkin dialami oleh pembelajar (Lado, 1965).

Ketika santri membaca, ustad/ustad tidak melakukan kegitana yang sama (wawancara Nopember 2016). Seorang pendidik seharusnya memberi teladan yang baik bagi peserta didiknya. Teladan yang baik tidak hanya berupa ujaran, tetapi juga mencakup tindakan (Suwarsih Madya, 2013: 113). Baik santri maupun ustad/ustazah sebaiknya secara bersama-sama membaca. Dengan demikian, seluruh stakeholder menjadi literat sesuai visi PMI-DM. Di samping itu, pembelajaran sangat dipengaruhi oleh faktor internal dan faktor eksternal, termasuk pembiasaan literasi sangat ditentukan oleh lingkungan sekitar.

Selanjutnya sarana dan prasarana untuk menunjang pembiasaan literasi masih terbatas, khususnya ketersediaan perpustakaan yang representatif dan sumber-sumber belajar yang memadai memang masih minim. Pembiasaan literasi harus dimulai dari halhal mendasar tersebut agar kebutuhan literasi terpenuhi dengan baik dengan harapan seluruh komponen pun menjadi literat. Selain itu, ketersediaan sumber belajar masih bergantung pada buku, padahal ada banyak yang dapat dijadikan sumber belajar, seperti lingkungan sosial budaya, media massa, artikel, jurnal, komik, novel, puisi, dan sebagainya.

Pengajaran bahasa selalu saja berkaitan dengan konteks sosial, budaya, peradaban, dan politik, bahkan setiap metode pengajaran pun banyak dipengaruhi oleh faktor eksternal bahasa. Seperti dijelaskan oleh Stern (1983: 269), faktor-faktor konteks sosial juga ikut memengaruhi pembelajaran bahasa. Senada dengan itu, Kumavadivelu (2012: 12-14) mengklasifikasi tiga parameter pembelajaran bahasa, yaitu: prinsip kekhususan/particularity (pengajaran dan pembelajaran bahasa harus mempertimbangkan aspek siswa, institusi, konteks sosial, dan budaya) prinsip kepraktisan/practicality (bermakna bagaimana sebuah teori dapat diaplikasikan dalam dunia nyata), prinsip possibility/kemungkinan (tepat secara sosial, budaya, dan politis). Jadi sumber belajar tidak terbatas pada buku teks.

\section{SIMPULAN}

Program "Gemar Membaca" disusun sebagai upaya mencapai visi Pesantren Modern Internasional Dea Malela (PMI-DM). Program tersebut memang masih baru, sehingga butuh komitren semua pihak agar sungguh-sungguh mendukungnya. Selain itu, program ini sangat relevan dengan visi PMI-DM yang mengusung berkeunggulan 
kompetitif, komparatif, dan dinamis. Program "Gemar Membaca" bertujuan untuk mengondisikan dan membiasakan santri dan stakeholder agar literat. Selain itu, tentu sebagai upaya mendukung tercapainya visi PMI-DM.

Selama ini, Program "Gemar Membaca" dilaksanakan melalui tiga tahap, yaitu: pramembaca, membaca, dan pascamembaca. Dalam pelaksanannya, masih ditemukan kekurangan baik dari sisi santri, ustad/ustazah, sumber belajar, prasarana, dan sebagainya. Namun demikian, program ini layak mendapat apresiasi karena telah mencoba membiasakan budaya literasi.

\section{REFERENSI}

Bialystok, E. (2003). Bilingualism in Development: Language, Literacy, and Cognition. Cambridge: Cambridge University Press.

http://www.bps.go.id/linkTabelDinamis/view/id/1211.

Ingulsrud, J. E., \& Allen, K. (2009). Reading Japan Cool: Patterns of Manga Literacy and Discourse. New York: Rowman \& Littlefield Publishers, Inc.

Ivanic, R. \& Hamilton, M. (1990). Literacy Beyond School. Dalam Wray, D. (Ed.)., Emerging Partnerships:Current Research in Language and Literacy, pp. 4-19. Clevedon: Multilingual Matters Ltd.

Kumaravadivelu. (2012). Language Teacher Education for a Global Society: A Modular Model for Knowing, Analyzing, Recognizing, Doing, and Seeing. New York: Routledge.

Lado, R. (1965). Linguistics across cultures. New York: McGall-Hill.

Luke, A., \& Carrington, V. (2002). Globalisation, Literacy, Curriculum Practice. Dalam Fisher, R., Brooks, G., \& Lewis, M. (Eds.)., Raising Standards in Literacy, pp. 231-250. London: Routledge.

OECD. (2000). Literacy in the Information Age: Final Report of the International Adult Literacy Survey. Paris \& Ottawa: OECD. (2012). PISA 2012 Results in Focus: What 15-Year-Olds Know and What They Can Do with What They Know. Paris: OECD Publishing. (2015). PISA 2015: PISA Results in Focus. Paris: OECD Publishing.

Permendikbud RI Nomor 23 Tahun 2015 tentang Penumbuhan Budi Pekerti.

Rhyner, P. M., Haebig, E. K., \& West, K. M. (2009). Understanding Frameworks for the Emergent Literacy Stage. Dalam Paula M. Rhyner (Ed.)., Emergent Literacy and Language Development: Promoting Learning in Early Childhood. London: The Guilford Press.

Ricards, J. C. (2006). Communicative Language Teaching Today. Cambridge: Cambridge University Press.

Roger Beard. (2002). As the Research Predicted? Examining the Success of the National Literacy Strategy. Dalam Fisher, R., Brooks, G., \& Lewis, M. (Eds.)., Raising Standards in Literacy, pp. 38-54. London: Routledge.

Rowe, B. M., \& Levine, D. P. (2009). A Concise Introduction to Linguistics (2 ${ }^{\text {nd }}$ Edition). Boston: Pearson Education, Inc.

Stern. H.H. (1983). Fundamental Concept of Language Teaching. London: Oxpord University Press.

Suwarsih Madya. (2013). Metodologi Pengajaran Bahasa: Dari Era Prametode Sampai Era Pascametode. Yogyakarta: UNY Press. 
Wray, D., et.al. (2004). Teaching Literacy Effectively in the Primary School. New York: Taylor \& Francis.

World Economic Forum. (2011). The Indonesia Competitiveness Report 2011: Sustaining the Growth Momentum. Geneva: World Economic Forum Bekerjasama dengan Center for Global Competitiveness serta Center for Regional Strategies' Asia Team.

www.deamalelafoundation.com. 